\title{
INTRINSIC HUMAN CAPACITIES OF HIGH AND LOW PERFORMERS OF PUBLIC SECTOR MANUFACTURING INDUSTRY IN INDIA
}

\author{
Dr. Shilpa Jain \\ University School of Management Studies, \\ Guru Gobind Singh Indraprastha University, Delhi, India \\ Preeti Singh \\ University School of Management Studies, \\ Guru Gobind Singh Indraprastha University, Delhi, India
}

\begin{abstract}
Background: Public Sector Manufacturing Industry in India has well dominated the culture of satisfactory under-performance in the past, wherein even low performance is seen as satisfactory as a Governmental promotion strategy. However, with time, the Public Sector's monopolistic existence has witnessed entry of new private players as their competitors and compelled them to perform at an equal platform, if not better. The change has geared the overall Management perspective/ strategy of Manufacturing Industry and the focus has shifted from mere existence to profitable existence. The approach has turned performance-oriented. Human capabilities driving organizational results are being acknowledged and organizations are increasingly spending more on enhancing their employee's Intrinsic Human Capacities. Keeping in view of the uniqueness of each human individual, this study was undertaken to examine whether different intrinsic human capacities (Learning capacity, Conceptual Capacity, Relationship Capacity, Action Capacity and Spiritual Intelligence) drives different degree of performance. Further, the study is based on the premises that individuals with higher intrinsic human capacities will perform better than those with lower intrinsic human capacities.
\end{abstract}

Materials and Methods: In this stratified randomized study, primary data from 399 executives of Public Sector Manufacturing Organization (with special status i.e. Maharatna, Navratna, Mini-ratna) in India was collected through self-administered questionnaires reports on five intrinsic human capacities (Learning capacity, Conceptual Capacity, Relationship Capacity, Action Capacity and Spiritual Intelligence). Performance scores from supervisors of these 399 executives were separately collected. Further, based on performance scores, the sample was categorized into five performance groups (Very High, High, Average, Low and Very Low). Finally, the overall data was statistically analyzed through ANOVA.

Results: Findings suggest that there is significant difference in the overall Intrinsic Human Capacities Scores of high and low performers of public sector 
manufacturing industry. In all the five intrinsic human capacities, there exists significant difference in high and low performers of public sector manufacturing industry, except for Learning capacity.

Conclusion: The study provides empirical support for researchers and practitioner in the field of Human Resource Development, directing training interventions for enhancing such intrinsic human capacities for higher performance. Dunning Krugers effect for overestimated intrinsic human capacities scores in 'Very Low Performance' group is also seen.

Keywords: Intrinsic Human Capacities; Learning Capacity; Conceptual Capacity; Relationship Capacity; Action Capacity; Spiritual Intelligence and Performance.

Cite this Article: Dr. Shilpa Jain, Preeti Singh, Intrinsic Human Capacities of High and Low Performers of Public Sector Manufacturing Industry in India, International Journal of Management (IJM), 10 (6), 2019, pp. 261-274.

$\mathrm{http}: / /$ iaeme.com/Home/issue/IJM?Volume $=10 \&$ Issue $=6$

\section{INTRODUCTION}

"The capabilities of human mind are enormous. There is usually no inherent reason you cannot accomplish whatever goal you set for yourself".

- Michael J. Mccarthy

Every human being is unique in nature. The rule of generalization does not usually apply to human behavior as each individual behaves differently under different circumstances, owing to their innate capabilities like genetic, physical, mental, social etc. There lies unpredictability in human nature which has drawn interest of various researchers in the field of social \& managerial science in the past and it still offers the opportunity of the unexplored to be researched more.

Public Sector Manufacturing Industry in India was established as a Governmental promotion strategy towards self sufficient India. The industry has well dominated the culture of satisfactory under-performance in the past, wherein even low performance is seen as satisfactory. However, with time, the Public Sector's monopolistic existence has witnessed entry of new private players as their competitors and compelled them to perform at an equal platform, if not better. The change has geared the overall Management perspective/ strategy of Manufacturing Industry and the focus has shifted from mere existence to profitable existence. The approach has turned performance-oriented. Human capabilities driving organizational results are being acknowledged and organizations are increasingly spending more on enhancing their employee's Intrinsic Human Capacities. This research paper is focused on important intrinsic human capacities (Capacity to learn, Capacity to think, Capacity to relate, Capacity to act and Spiritual Intelligence) which are presumed to be the foundation stone of desired positive work behaviors/ outcomes in Indian working culture.

Keeping in view of the uniqueness of each human individual, this study was undertaken to examine whether different intrinsic human capacities (Learning Capacity, Conceptual Capacity, Relationship Capacity, Action Capacity and Spiritual Intelligence) drives different degree of performance and is based on the premises that individuals with higher intrinsic human capacities will perform better than those with lower intrinsic human capacities. The objective is to generate desired performance by enhancing five Intrinsic Human Capacities including Learning Capacity, Conceptual Capacity, Relationship Capacity, Action Capacity and Spiritual Intelligence of executives of Public Sector Manufacturing Industry. 


\section{REVIEW OF LITERATURE}

Performance, Job satisfaction, Work happiness and Organizational Commitment are desired work related employee outcomes which are related to employee's positive psychological resource capacities ${ }^{[1]}$. In addition, the various professional aspects of an individual's life (including compensation, working conditions, opportunities to use and develop human capacities, opportunity for continued growth and security, social integration in the work organization, work and total life space, and social relevance of the work life) have also been positively related to work outcomes as it has a direct effect on performance ${ }^{[2][3][4][5]}$ as they focus on healthier, more satisfied and more productive employees and more efficient, adaptive and profitable organization ${ }^{[6]}$. Individuals usually perceive differently because they are different on their interpersonal skills and intrinsic capacities, which in turn affects their performance ${ }^{[7][8]}$.

There exist evidences in the social science and management literature to support the understanding that individual differences impact on work performance. Psychological differences also impact on individuals' ability to engage or disengage in their role performance, because they shape a person's ability and willingness to be involved or committed at workplace. Accordingly, people would engage differently "given their experiences of psychological meaningfulness, safety and availability in specific situations" [9]. For example, when people experience situations as unsafe, it is a matter of individual differences what coping strategies they deploy, and the extent to which they engage or disengage ${ }^{[10]}$. The process of perception is a key factor in individual behavior. To a large extent, perception relates to the way in which individuals make sense of their environment and interpret and respond to the events and people around them. Equally, it is important to emphasize that each individual receives information differently. This is because individuals do not receive information about what is happening around them passively and dispassionately or in the same way as others. Individuals categorizes and make sense of events and situations according to their own unique and personal frame of reference, which reflects their personality, past experiences, knowledge, expectations and current needs, priorities and interests ${ }^{[11][12]}$.

Human resource with superior intellectual capital is the need of today's highly volatile business environment. Therefore, organizations bear a continuous pressure to build competence for higher level of performance. An individual's ability to handle such volatile pressure will increase the likelihood that he or she is able to find positive benefits from challenging events ${ }^{[13][14]}$, reflect on the experience after it has occurred, and ultimately learn from that experience. Specifically, effective individuals refuse to be paralyzed by uncertainty and unpredictable work situations by resisting the temptation to over analyze and by taking effective action even when the total picture or all the facts are not at hand ${ }^{[15]}$. We also believe, as others do, that development of intrinsic human capacities (Capacity to learn, Capacity to think, Capacity to relate and Capacity to act) are fundamental to the concept of Talent Management ${ }^{[16]}$ which will further enhance the abilities and key result areas of the job. Dr.Dilip B. Patil, Dr.Dinesh D.Bhakkad [17], in their edited book 'Redefining Management Practices and Marketing in Modern Age' have also mentioned these capacities as a focus of talent management. These abilities will form the core competencies of the talent reservoir. Talent management enhances the potential of the people by developing these capacities, called the basic DNA of an organization and also of an individual's potential ${ }^{[18]}$.

'Intrinsic human capacities' is a newly proposed model for talent management [19] requiring empirical support, according to which individuals get motivated by different value propositions. To keep the workforce motivated, organizations today have to adopt certain practices like: 
1. Learning Capacity: Capacity to learn [measured as Learning Quotient (LQ)]. Enhancing an individual's capacity to learn improves the person's awareness towards his work. Different researchers have defined \& used the term differently, as learning capacity, learnability and learning agility.

Learnability is defined as the ability to adapt to new situations and the ability to understand the rules of a changing game and excel at them ${ }^{[20]}$. Learnability is important because it is the single most important factor that determines the pace at which an individual grows.

Learning agility is defined as the willingness and ability to learn from experience, and subsequently apply that learning to perform successfully under new or first-time conditions ${ }^{[21][22]}$. Mitchinson, A. G., Gerard, N. M., Roloff, K. S., \& Burke, W. (2012) ${ }^{[23]}$ in their white paper 'learning about learning agility' defined it as a collection of behaviors that individuals employ as they seek out, manage, understand, and ultimately learn from challenging organizational experiences.

2. Conceptual Capacity: Capacity to think [measured as Conceptual Quotient (CQ)]. Enhancing an individual's capacity to think helps the person not only learning for a higher level, but also improves Creativity, Analysis and Judgments.

If an individual lacks conceptual work capacity to generate the thought processes required to encompass the complexity inherent in his or her work responsibilities, then effective discretion cannot be exercised. Individual differences in conceptual capacity are highly relevant to leader effectiveness, particularly at upper organizational levels. Individuals differ in their capacity to conceptually grasp and manage complex managerial and leadership ${ }^{[24]}{ }^{[25]}$.

$\mathrm{CQ}$ is a measure of discrepancy between vocabulary scores and abstraction scores, according to Malerstein ${ }^{[26] . ~ S h i p l e y ~ d e f i n e d ~ i t ~ a s ~ a n ~ i n d e x ~ o f ~ i n t e l l e c t u a l ~ i m p a i r m e n t ~ b a s e d ~ o n ~}$ discrepancy between obtained abstraction scores and abstraction scores to be expected from vocabulary scale ${ }^{[27]}$.

Individuals with higher $\mathrm{CQ}$ are characterized by capacity for independent thought unconstrained by shared or consensus views of reality. These individuals are able to think about rather than thinking within shared points of view and are broader thinkers. The internalization of personal standards and values at the higher stage also imparts a greater psychological distance from the shared frames characteristic of individuals, thereby imparting greater objectivity about what others or the organization thinks and expects ${ }^{[28]}$.

3. Relationship Capacity: Capacity to relate [measured as Relationship Quotient (RQ)].Another important capacity for an individual is to be able to relate to his learning and thoughts. This comprises of Listening, Empathizing and Trusting.

Relationship capacity is measured by relationship quotient, also referred as People Quotient (PQ) which is relating to and working through people. As per, Tushar Soubhari \& Dr. Yathish Kumar ${ }^{[19]}$ PQ has three aspects to it, and each aspect includes both understanding the effects of different types of behavior and acting in accordance with that understanding. Its three aspects include: Self-Management, openness to others, and interpersonal effectiveness. Friendship and relationship quotient created by Baron- Cohen \& Wheelright ${ }^{[29]}$ measures the extent to which participants "enjoyed close, empathic supportive friendship; who liked and were interested in people, who enjoyed interaction with others for its own sake; and for whom friendship/relationship is important". Relationship intelligence (measured by RQ) comprises of one's ability to perceive, assess and manage his/her relationships ${ }^{[30]}$. It involves gaining an understanding of ourselves and others and applying that understanding to build more meaningful and effective relationships. 
4. Action Capacity: Capacity to act [measured as Action Quotient (AQ)] Action is an individual's ability to enact his intentions - ability to organize his time and resources in order to convert intentions into reality.

"Action quotient" (AQ) is the ratio found by dividing the number of "active" expressions or verbs by the number of "qualitative" expressions or adjectives per 100 words, according to Feldman. Action Quotient has also been analogically used as Achievement Quotient (AQ). It involves an assessment to rate how a student/youth performed on 21 st century skills. The parameters used for analysis of Achievement Quotient are Personal Mindset, Planning for Success, Social Awareness, Verbal Communication, Collaboration and Problem Solving ${ }^{[19]}$.

The role of development of various other intrinsic human capacities - consciousness, communication, language, thinking, speaking, writing has also been documented in the pursuant of liberal arts, as well ${ }^{[31][32]}$. Thinking is not entirely cerebral, not just IQ, as we think with our heads but also with our emotions and our bodies (EQ) and our spirits, our values, our hopes, our unifying sense of meaning and value (SQ), and whether mind has a quantum dimension. Spiritual Intelligence is about having a direction in life, and being able to heal ourselves of all the resentment--- It is thinking of ourselves as an expression of a higher reality ${ }^{[33]}$. Another study states that intelligence Quotient (IQ) and Emotional Quotient (EQ) together are not able to explain the full complexity of human intelligence \& imagination. There is a third kind of quotient which makes it possible for human beings to do creative, insightful, rule-making or breaking thinking. It is known as spiritual intelligence and can also be called as Spiritual Quotient ${ }^{[34]}$. Spiritual Quotient is the spectrum against which we assess the usefulness of one life path or the need to change the particular direction one's actions are taking. Intelligence, emotional, and spiritual quotients (IESQ) has been predicted to escalate

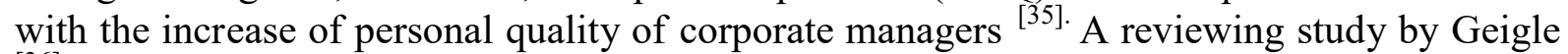
${ }^{[36]}$ of workplace spirituality indicated that workplace spirituality (WS) has been empirically tested in many organizations across several countries and demonstrated a positive effect of WS on job commitment, satisfaction, and performance.

Thus, understanding employees at individual level and their intrinsic human capacities are important. Cognitive human capacity enhancement could offer significant social and economic benefits ${ }^{[37]}$. Accordingly, based on past empirical evidences of various intrinsic human capacities on performance, five (Learning Capacity, Conceptual Capacity, Relationship Capacity, Action Capacity and Spiritual Intelligence) have been included in the instant research paper and their impact on the performance has been studied.

\section{RESEARCH METHODOLOGY}

\subsection{Objective of the Study}

As an additional empirical support to existing research, the present study aims to study impact of five "Intrinsic Human Capacities - (Learning Capacity, Conceptual Capacity, Relationship Capacity, Action Capacity and Spiritual Intelligence)" on performance of executives of Public Sector Manufacturing Industry in India.

\subsection{Hypotheses}

H1: There is a significant difference in the Learning Capacity of high and low performers of Public Sector Manufacturing Industry in India.

$\mathrm{H} 2$ : There is a significant difference in the Conceptual Capacity of high and low performers of Public Sector Manufacturing Industry in India.

H3: There is a significant difference in the Relationship Capacity of high and low performers of Public Sector Manufacturing Industry in India. 
H4: There is a significant difference in the Action Capacity of high and low performers of Public Sector Manufacturing Industry in India.

H5: There is a significant difference in the Spiritual Intelligence of high and low performers of Public Sector Manufacturing Industry in India.

H6: There is a significant difference in the Overall score of Intrinsic Human Capacities (IHC) of high and low performers of Public Sector Manufacturing Industry in India.

\subsection{Sample and Respondents}

The study is limited to Public Sector Manufacturing Organization with special status like Maharatna, Navratana, Mini-Ratna, listed on the official website of DPE (Department of Public Enterprise). 399 working executives in Public Sector manufacturing organizations (including Bharat Electronics Limited, Bharat Heavy Electrical Limited, National Thermal Power Plant, National Fertilizers Limited etc.) participated in the present study.

\subsection{Scale/ Measure used in the Research}

Empirical data was collected by 42 items self- administered questionnaire measuring four dimensions: Learning Capacity, Conceptual Capacity, Relationship Capacity and Action Capacity on five point likert's scale. For Spiritual Intelligence, SISRI-24 instrument was used. Performance was measured by 13 itemed Lather and Jain's Scale, through scores assigned by supervisors of these 399 executives.

\subsection{Data Collection}

Working executives employed in aforementioned public sector manufacturing organization were contacted and explained the purpose of the research. On their consent, executives were given questionnaires to mark their candid responses. Later, supervisors of these executives were contacted through HR Department and they were requested to award scores on 13 attributes of Performance on 5 point scale.

The duly filled in questionnaires submitted were used in further data analysis. The overall IHC scores were calculated through combined scores of Learning Capacity, Conceptual Capacity, Relationship Capacity, Action Capacity and Spiritual Intelligence. The executives were categorized into five groups based on their scores on the level of performance (i.e. Very High, High, Average, Low and Very Low).

\subsection{Statistical Analysis}

Data was analyzed using SPSS, primarily using ANOVA. The level $P<0.05$ was considered as the cutoff value or significance.

\section{RESULTS AND FINDINGS}

The primary data collected on various Intrinsic Human capacities and levels of performance was statistically analyzed through ANOVA. The ANOVA Table (TABLE No-1) revealed that there is significant difference in Learning Capacity, Conceptual Capacity, Relationship Capacity, Action Capacity, Spiritual Intelligence and Overall Intrinsic Human Capacities Score (IHC) across various performance levels (i.e. Very High, High, Average, Low and Very Low) of executives of Public Sector Manufacturing Industry in India, with values for Learning Capacity, Conceptual Capacity, Relationship Capacity, Action Capacity, Spiritual Intelligence and Overall Intrinsic Human Capacities Score $(\mathrm{IHC})$ as $(\mathrm{F}$ value $=5.80, \mathrm{p}$ value $=$ $.000),(\mathrm{F}$ value $=5.14 \mathrm{p}$ value $=.000),(\mathrm{F}$ value $=5.06, \mathrm{p}$ value $=.001), \quad(\mathrm{F}$ value $=6.65, \mathrm{p}$ 
value $=.000),(\mathrm{F}$ value $=15.14, \mathrm{p}$ value $=.00)$ and $(\mathrm{F}$ value $=10.01, \mathrm{p}$ value $=.000)$ respectively.

Table 1 Shows Intrinsic Human Capacities of five performance groups

\begin{tabular}{|c|c|c|c|c|c|c|}
\hline & & Sum of Squares & df & Mean Square & $\mathbf{F}$ & Sig \\
\hline \multirow{3}{*}{ Learning Capacity } & Between Groups & 5.46 & 4 & 1.36 & 5.80 & .000 \\
\hline & Within Groups & 92.76 & 394 & .23 & & \\
\hline & Total & 98.23 & 398 & & & \\
\hline \multirow[t]{3}{*}{ Conceptual Capacity } & Between Groups & 5.56 & 4 & 1.39 & 5.14 & .000 \\
\hline & Within Groups & 106.51 & 394 & .27 & & \\
\hline & Total & 112.07 & 398 & & & \\
\hline \multirow{3}{*}{ Relationship Capacity } & Between Groups & 7.41 & 4 & 1.85 & 5.06 & .001 \\
\hline & Within Groups & 144.21 & 394 & .36 & & \\
\hline & Total & 151.63 & 398 & & & \\
\hline \multirow{3}{*}{ Action Capacity } & Between Groups & 5.98 & 4 & 1.49 & 6.65 & .000 \\
\hline & Within Groups & 88.58 & 394 & .22 & & \\
\hline & Total & 94.57 & 398 & & & \\
\hline \multirow[t]{3}{*}{ Spiritual Intelligence } & Between Groups & 18.67 & 4 & 4.66 & 15.14 & .000 \\
\hline & Within Groups & 121.42 & 394 & .30 & & \\
\hline & Total & 140.09 & 398 & & & \\
\hline \multirow{3}{*}{$\begin{array}{l}\text { Over Intrinsic Human } \\
\text { Capacities Score } \\
\text { (IHC) }\end{array}$} & Between Groups & 5.92 & 4 & 1.48 & 10.01 & .000 \\
\hline & Within Groups & 58.28 & 394 & .14 & & \\
\hline & Total & 64.20 & 398 & & & \\
\hline
\end{tabular}

The scrutiny of TABLE No.2 shows that the executives of "Very High" performance level are significantly higher on Learning Capacity, Conceptual Capacity, Relationship Capacity, Action Capacity, Spiritual Intelligence and Overall Intrinsic Human Capacities Score (IHC) than rest of the performance groups.

Table 2 Level of performance wise significant mean difference among five intrinsic human capacities and overall intrinsic human capacities scores.

\begin{tabular}{|l|c|c|c|c|c|}
\hline \multicolumn{1}{|c|}{ Dependent Variable } & Very High & High & Average & Low & $\begin{array}{c}\text { Very } \\
\text { Low }\end{array}$ \\
\hline Learning Capacity & $3.80_{\mathrm{a}}$ & $3.49_{\mathrm{c}}$ & $3.72_{\mathrm{ab}}$ & $3.62_{\mathrm{bc}}$ & $3.80_{\mathrm{a}}$ \\
\hline Conceptual Capacity & $3.97_{\mathrm{a}}$ & $3.69_{\mathrm{b}}$ & $3.63_{\mathrm{b}}$ & $3.67_{\mathrm{b}}$ & $3.78_{\mathrm{b}}$ \\
\hline Relationship Capacity & $4.31_{\mathrm{a}}$ & $4.01_{\mathrm{b}}$ & $3.90_{\mathrm{b}}$ & $4.01_{\mathrm{b}}$ & $4.10_{\mathrm{b}}$ \\
\hline Action Capacity & $3.96_{\mathrm{a}}$ & $3.72_{\mathrm{b}}$ & $3.59_{\mathrm{b}}$ & $3.65_{\mathrm{b}}$ & $3.73_{\mathrm{b}}$ \\
\hline Spiritual Intelligence & $2.92_{\mathrm{a}}$ & $2.86_{\mathrm{a}}$ & $2.47_{\mathrm{b}}$ & $2.38_{\mathrm{b}}$ & $2.80_{\mathrm{a}}$ \\
\hline $\begin{array}{l}\text { Over Intrinsic Human Capacities Score } \\
\text { (IHC) }\end{array}$ & $3.79_{\mathrm{a}}$ & $3.55_{\mathrm{bc}}$ & $3.46_{\mathrm{c}}$ & $3.47_{\mathrm{c}}$ & $3.64_{\mathrm{b}}$ \\
\hline $\begin{array}{l}\text { Note: Means with differing subscripts within rows are significantly different at the } \mathrm{p}<.05 \text { based on } \\
\text { Duncan Multiple Range post hoc paired comparisons. }\end{array}$
\end{tabular}

\subsection{Learning Capacity}

There is significant difference in the learning capacity of (a) Very high, Average, Very low; (b) Average, Low and (c) High, Low performance groups. The executives of 'Very High' performance group have highest mean score of 3.807. 'High' performance group (3.49) has lower scores than 'Average' performance group (3.72) and 'Low' performance group. Ironically, 'Very Low' performance group (3.801) has a lower but comparable mean score to 'very high' performance group. 


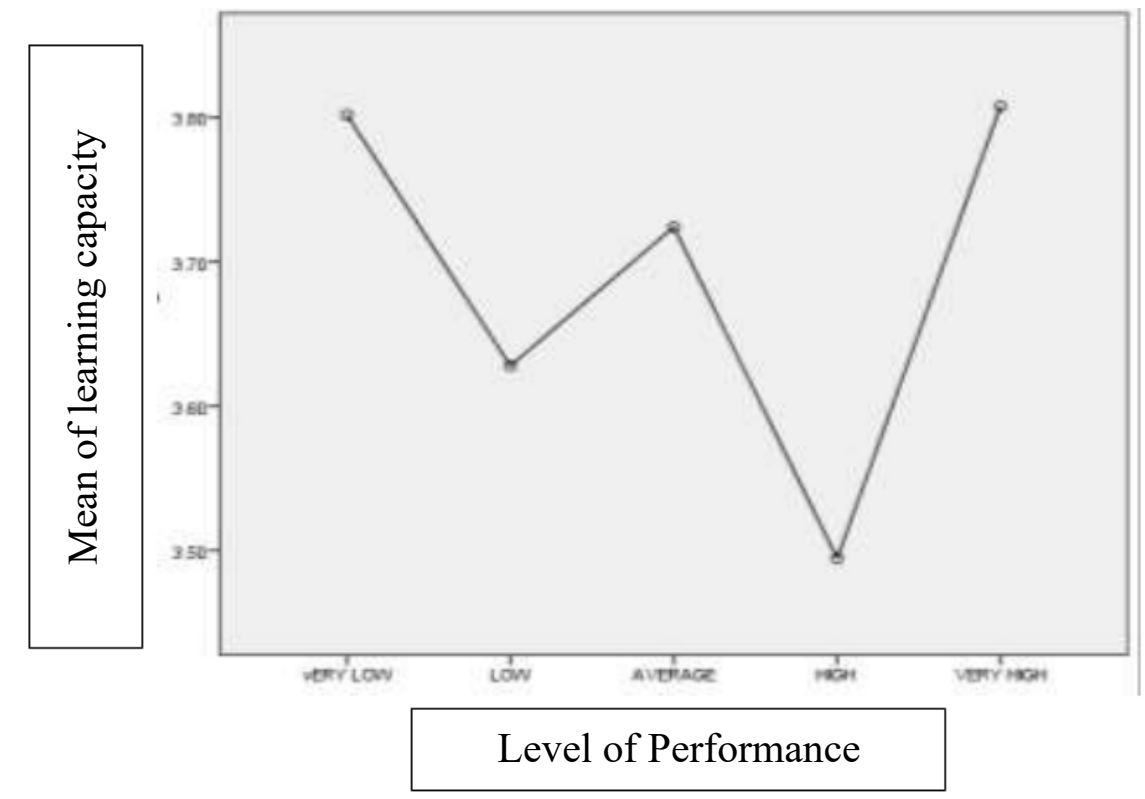

Figure 1: Mean plot for Learning Capacity

\subsection{Conceptual Capacity}

There is significant difference in the conceptual capacity of (a) Very high and (b) High, Average, Low and Very Low performance groups. The executives of 'Very High' performance group have highest mean score of 3.97. 'High' performance group (3.694) and 'Low' performance group (3.671) has higher scores than 'Average' performance group (3.63). Ironically, 'Very Low' performance group (3.78) has a lower but comparable mean score to 'very high' performance group. 'Very Low' performance group has higher score than high, average and low performance groups.

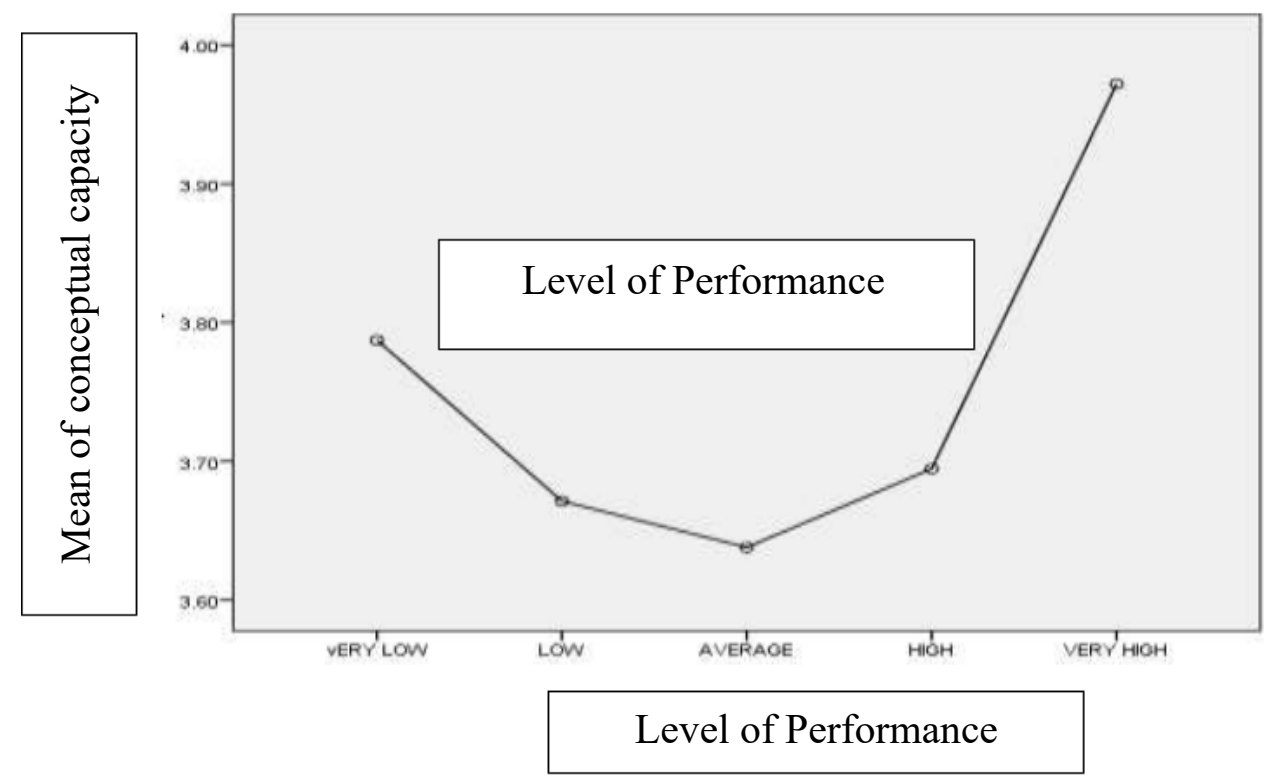

Figure 2: Mean plot for Conceptual Capacity

\subsection{Relationship Capacity}

There is significant difference in the relationship capacity of (a) Very high and (b) High, Average, Low and Very Low performance groups. The executives of 'Very High' performance group have highest mean score of 4.31. 'High' performance group (4.013) and 
'Low' performance group (4.01) has higher scores than 'Average' performance group (3.90). Ironically, 'Very Low' performance group (4.10) has a lower but comparable mean score to 'very high' performance group. 'Very Low' performance group has higher score than high, average and low performance groups.

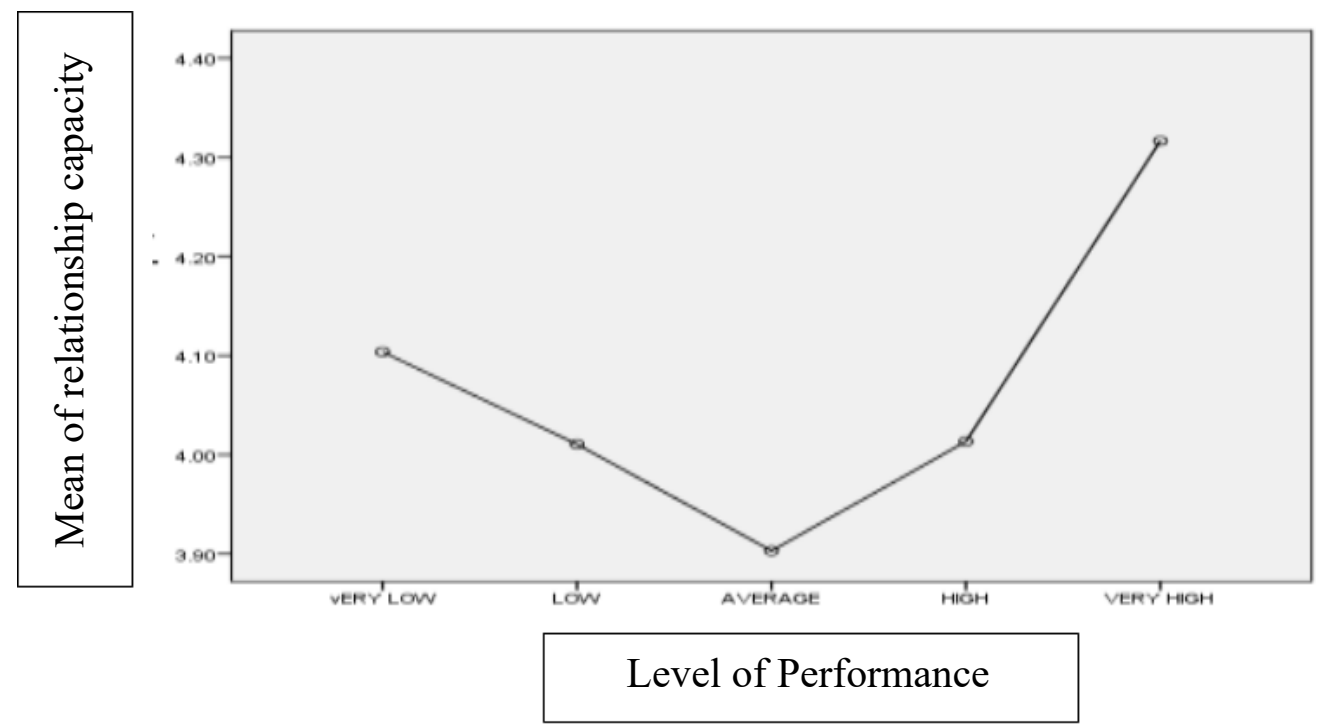

Figure 3: Mean plot for Relationship Capacity

\subsection{Action Capacity}

There is significant difference in the action capacity of (a) Very high and (b) High, Average, Low and Very Low performance groups. The executives of 'Very High' performance group have highest mean score of 3.96. 'Average' performance group (3.59) has lower scores than 'High' performance group (3.72) and 'Low' performance group (3.65). Ironically, 'Very Low' performance group (3.73) has a lower but comparable mean score to 'very high' performance group. 'Very Low' performance group has higher score than high, average and low performance groups.

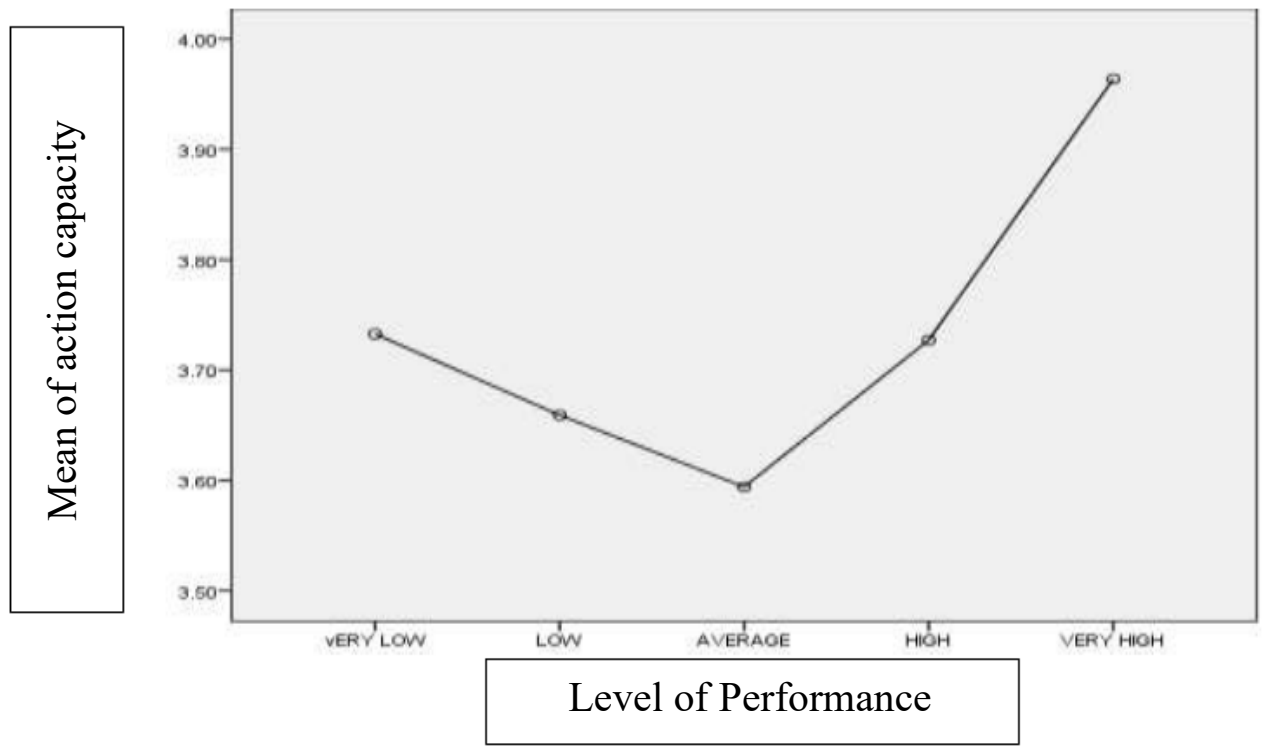

Figure 4: Mean plot for Action Capacity 


\subsection{Spiritual Intelligence}

There is significant difference in the spiritual intelligence of (a) Very high, High, Very Low and (b) Average and Low performance groups. The executives of 'Very High' performance group have highest mean score of 2.92. 'High' performance group (2.86) has higher scores than 'Average' performance group (2.47) and 'Low' performance group (2.38). Ironically, 'Very Low' performance group (2.80) has a higher mean score than 'Average' and 'Low' performance group.

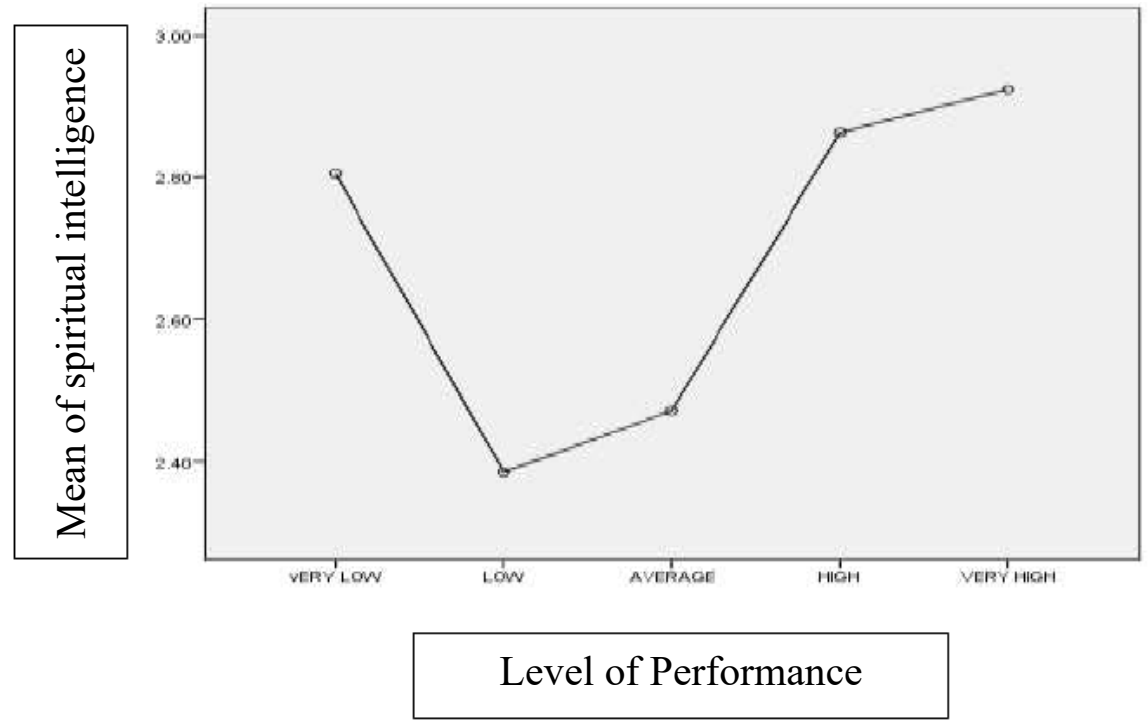

Figure 5: Mean plot for Spiritual Intelligence

\subsection{Overall Intrinsic Human Capacities Score (IHC)}

There is significant difference in the overall intrinsic human capacities score of (a) Very high; (b) High, Very Low and (c) High, Average and Low performance groups. The executives of 'Very High' performance group have highest mean score of 3.97. 'High' performance group (3.55) has higher scores than 'Average' performance group (3.46) and 'Low' performance group (3.47). Ironically, 'Very Low' performance group (3.64) has a lower but comparable mean score to 'very high' performance group. 'Very Low' performance group has higher score than high, average and low performance groups.

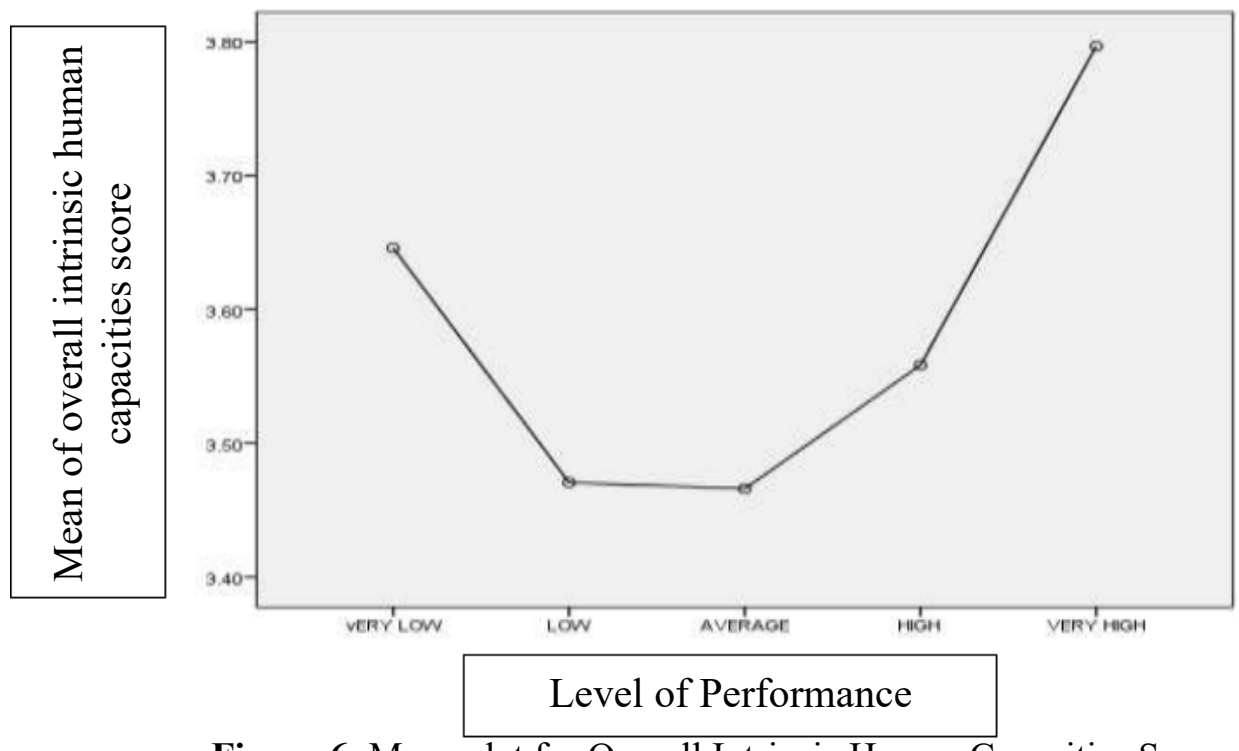

Figure 6: Mean plot for Overall Intrinsic Human Capacities Score 


\section{DISCUSSION}

The executives of "Very High" performance level are significantly higher on Learning Capacity, Conceptual Capacity, Relationship Capacity, Action Capacity, Spiritual Intelligence and Overall Intrinsic Human Capacities Score (IHC) than rest of the performance groups. This is in line with the existing research that individuals with higher intrinsic human capacities are more aware and competent of handling work life challenges and produce desired output in the form of work performance.

Individuals with higher learning capacity are more willing/ open to learn from routine circumstances and apply their learning to new demanding situations. They are aware of surroundings and are able to manage innovation. They are more open to change. Individuals with higher conceptual capacity are more likely to drive experiences/ thoughts from past and address challenges with critical analysis and creativity. They are able to think problems critically and drive solutions. Individuals with high relationship capacity are more able to manage diversity and teams' dynamics. They use their inter-personal skills to their advantage in social and professional life. Individuals with high action capacity are more result oriented and exhibit accountability. They are able to deal with ambiguity in everyday life wisely. Individuals with higher spiritual intelligence are critical thinkers and bear clarity of mind. Since, the executives with higher intrinsic capacities (Learning Capacity, Conceptual Capacity, Relationship Capacity, Action Capacity and Social Intelligence) imbibes higher positive aspects to drive their efforts, therefore, they lead in work performance level, as supported by empirical evidences in the study.

Further, unlike expected, 'Very Low' performance group has shown comparable mean score to 'very high' performance group. 'Very Low' performance group has also shown higher score than 'High' and/or 'Average' and/or 'Low' performance groups. This could be due to Dunning-Kruger effect, a cognitive bias whereby people with limited knowledge or competence in a given intellectual or social domain greatly overestimate their own knowledge or competence in that domain relative to objective criteria or to the performance of their peers or of people in general.

\section{CONCLUSION}

Executives possessing higher intrinsic human capacities like Learning Capacity, Conceptual Capacity, Relationship Capacity, Action Capacity and Social Intelligence are high performing individuals in Public Sector Manufacturing Industry in India. All the hypotheses are supported by empirical evidences in the instant study. Brief of the same is as under:-

H1: There is a significant difference in the Learning Capacity of high and low performers of Public Sector Manufacturing Industry in India- Supported.

$\mathrm{H} 2$ : There is a significant difference in the Conceptual Capacity of high and low performers of Public Sector Manufacturing Industry in India- Supported.

H3: There is a significant difference in the Relationship Capacity of high and low performers of Public Sector Manufacturing Industry in India- Supported.

H4: There is a significant difference in the Action Capacity of high and low performers of Public Sector Manufacturing Industry in India- Supported.

H5: There is a significant difference in the Spiritual Intelligence of high and low performers of Public Sector Manufacturing Industry in India- Supported.

H6: There is a significant difference in the Overall score of Intrinsic Human Capacities (IHC) of high and low performers of Public Sector Manufacturing Industry in India- Supported. 


\section{LIMITATIONS OF THE STUDY}

Due to limited scope and other constraints, the present study has the following limitations;-

- Since the instrument used was self-report, there might be inconsistency between what respondents report and what they actually are. Conscious self-report and consequences of reporting personal information might introduce some errors in self- report responses.

- Ambiguity and lack of self-awareness on the part of respondents may introduce errors.

\section{FUTURE DIRECTIONS}

The study carries future research directions for Human Resource Development in the field of talent management, talent acquisition interventions, developing leadership qualities, individual \& organizational commitment and other desired workplace outcomes. Correlation with other positive workplace outcomes may also be established as a future extension of this study.

\section{REFERENCES}

[1] Youssef, C. M., \& Luthans, F. (2007). Positive Organizational Behavior in the Workplace. Journal of Management, 33(5), 774-800. doi:10.1177/0149206307305562

[2] Nguyen, Tho D. and Nguyen, T.T.M. (2012), “Psychological Capital, Quality of Work Life, and Quality of Life of Marketers: Evidence from Vietnam," Journal of Macromarketing, 32(1), 87-95.

[3] Baral, R., \& Bhargava, S. (2010). Work-family enrichment as a mediator between organizational interventions for work-life balance and job outcomes. Journal of Managerial Psychology, 25(3), 274-300. doi:10.1108/02683941011023749.

[4] Adeyemo, D. A. (2008). Demographic Characteristics and Emotional Intelligence among Workers in Some Selected Organisations in Oyo State, Nigeria. Vision: The Journal of Business Perspective, 12(1), 43-48. doi:10.1177/097226290801200106

[5] Lau (2000), Relationships among Asian American women. (2000). doi:10.1037/10349000 .

[6] Hackman JR, Suttle JL. Improving life at work: Behavioral science approaches to organizational change. Santa Monica, CA: Goodyear; 1977.

[7] Rao, Raghunathan, "TQM and Work Culture, An Empirical Analysis"; Productivity, 35, New Delhi, 1994.

[8] Narayan, Asit, and Jha, Amarnath, "Quality of Work Life - Concepts and Process", The Indian Journal of Commerce, Vol. XLV, December, 1992.

[9] Kahn, W. A., \& Fellows, S. (2013). Employee engagement and meaningful work. In B. J. Dik, Z. S. Byrne, \& M. F. Steger (Eds.), Purpose and meaning in the workplace (p. 105126). American Psychological Association. https://doi.org/10.1037/14183-006.

[10] Portello, J. Y., \& Long, B. C. (2001). Appraisals and coping with workplace interpersonal stress: A model for women managers. Journal of Counseling Psychology, 48(2), 144-156. doi:10.1037/0022-0167.48.2.144

[11] Robinson, I. (2006). Human Resource Management in Organisations. London, CIPD.

[12] Robinson D, Perryman, S. \& Hayday, S. (2004). The Drivers of Employee Engagement, Institute for Employment Studies, Brighton, Report 408, retrieved on December 14th, 2011.

[13] Kobasa, S. C. (1979). Stressful life events, personality, and health: an inquiry into hardiness. Journal of personality and social psychology, 37(1), 1. 
[14] Bennis, W. G., \& Thomas, R. J. (2007). Crucibles of Leadership. Leadership, 51-60. doi: 10.2307

[15] Pulakos, E. D., Arad, S., Donovan, M. A., \& Plamondon, K. E. (2000). Adaptability in the workplace: Development of a taxonomy of adaptive performance. Journal of Applied Psychology, 85(4), 612-624

[16] Mehta A. (2011), "Human Capital Management: A Comprehensive Approach to Augment Organizational Performance", Review of Management, Vol. 1, No. 2, April-June 2011

[17] Redefining Management Practices and Marketing in Modern Age edited by Dr.Dilip B.

Patil, Dr.Dinesh D.Bhakkad, 2014, pg-198, ebook

https://books.google.co.in/books?id=7DOVAgAAQBAJ

[18] Srivastava, R., \& Bhargava, S. Competency Mapping-A Strategic Approach In Talent Management, https://scholar.googleusercontent.com/scholar? q=cache:MlCmauw7 ByMJ:scholar.google.com/\&hl=en\&as_sdt $=0,5 \&$ as_ylo $=2008$

[19] Munivenkatappa, Nagaraja, G. and Bharathi, K.V. (2013), “ The Management Of Talents In Business Oganisations - A Study", Innovative Journal of Business and Management 2 : 4 July - August (2013) 49 - 55.

[20] SOUBHARI, T. (2012). Meditation At Workplace--- A Key Driving Performance Towards Organizational Change': An Experimental Survey Approach. Global Journal For Research Analysis, 3(4), 29-32. doi:10.15373/22778160/apr2014/10

[21] De Meuse, K. P., Dai, G., \& Hallenbeck, G. S. (2010). Learning agility: A construct whose time has come. Consulting Psychology Journal: Practice and Research, 62(2), 119130. doi:10.1037/a0019988.

[22] Lombardo, M. M., \& Eichinger, R. W. (2000). High potentials as high learners. Human Resource Management, 39(4), 321-329. doi:10.1002/1099-050x(200024)39:4<321::aidhrm4 $>3.0 . c 0 ; 2-1$

[23] Mitchinson, A. G., Gerard, N. M., Roloff, K. S., \& Burke, W. (2012). Learning about learning agility. Academy of Management Proceedings, 2012(1), 17742. doi:10.5465/ambpp.2012.288.

[24] Jaques, E. (1977). Conversation. Organizational Dynamics, 5(4), 24-43. doi:10.1016/0090-2616(77)90038-9

[25] Jaques, I. D. (1989). A Conversation with Dodgson's Niece. Lewis Carroll, 27-28. doi:10.1007/978-1-349-08724-2_15

[26] Malerstein, A. J. (1979). The Restoration of the Self. American Journal of Psychotherapy, 33(1), 142-143. doi:10.1176/appi.psychotherapy.1979.33.1.142

[27] Shipley, W. C., \& Burlingame, C. C. (1941). A Convenient Self-Administering Scale For Measuring Intellectual Impairment In Psychotics. American Journal of Psychiatry, 97(6), 1313-1325. doi:10.1176/ajp.97.6.1313

[28] Millgate, M. (1994). On Native Grounds: Charles Kegan Paul and William Barnes. Thomas Hardy, 117-129. doi:10.1057/9780230379534_10

[29] Baron-Cohen, S., \& Wheelwright, S. (2003). Journal of Autism and Developmental Disorders, 33(5), 509-517. doi:10.1023/a:1025879411971

[30] Meena Surie Wilson, Ellen Van Velsor, Anand Chandrasekar, and Corey Criswell (2016), White paper Center for Creative Leadership, (n.d.) Grooming Top Leaders Cultural Perspectives from China, India, Singapore, and the United States, Friendship and Relationship Quotient (FQ) doi:10.13072/midss.190

[31] Kessels, J. (2001). Socrates Comes to Market. Philosophy of Management, 1(1), 49-71. doi:10.5840/pom20011128 
[32] Korthagen, F. A., Kessels, J., Koster, B., Lagerwerf, B., \& Wubbels, T. (2001). Linking Practice and Theory. doi:10.4324/9781410600523

[33] Selman, V., Selman, R.C., Selman, J. and Selman, E. (2005), College Teaching Methods \& Styles Journal - Third Quarter 2005 Volume 1, Number 3, pp. 23-30.

[34] Srivastava, A. and Misra, S. (2012), "Is spiritual quotient a better tool of success: spirituality in the new world order", International Journal of Multidisciplinary Management Studies Vol.2 Issue 1, January 2012, ISSN 22498834.

[35] Haji, J., Bemby, A.B. and Sentosa, I. (2013), "The Intelligence, Emotional, Spiritual Quotients and Quality of Managers", Global Journal of Management and Business Research Administration and Management, Volume 13 Issue 3, Version 1.0 Year 2013, pp. 1-13.

[36] Geigle, D. (2012), “Workplace Spirituality Empirical Research: A Literature Review”, Business and Management Review Vol. 2(10), 2012, pp. 14 - 27.

[37] Sandberg, A., Sinnott-Armstrong, W., \& Savulescu, J. (2011). Cognitive Enhancement in Courts. Oxford Handbooks Online. doi:10.1093/oxfordhb/9780199570706.013.0067. 